\title{
TINGKAT PENGETAHUAN REMAJA PUTRI DALAM MENJAGA KEBERSIHAN ORGAN REPRODUKSI SAAT MENSTRUASI
}

\author{
Dewi Irianti*, Lydia Tiarahma \\ Program Studi Diploma Tiga Keperawatan Stikes Intan Martapura, Indonesia \\ Email : dewiiriantii@gmail.com
}

\begin{abstract}
ABSTRAK
Kesehatan reproduksi remaja putri harus diperhatikan untuk menghindari beberapa penyakit, diantaranya keputihan, kanker serviks, iritasi genital, alergi, peradangan dan infeksi saluran kemih. Diperlukan pengetahuan yang baik bagi remaja putri tentang kesehatan reproduksi agar tidak mengalami penyakit tersebut. Penelitian ini bertujuan untuk mengetahui tingkat pengetahuan remaja putri dalam menjaga kebersihan organ reproduksi saat menstruasi di Mts.Pangeran Antasari Martapura tahun 2020. Penelitian ini menggunakan metode deskriptif dengan desain cross sectional study. Populasi pada penelitian ini adalah remaja putri kelas VII,VIII, dan IX dengan jumlah 131 orang. Teknik pengambilan sampel adalah purposive sampling, sebanyak 60 orang. Instrument penelitian menggunakan kuesioner. Hasil penelitian menunjukkan tingkat pengetahuan responden tentang menstruasi $(91,7 \%)$, kebersihan organ reproduksi saat menstruasi $(60 \%)$, dan cara menjaga kebersihan organ reproduksi saat mentruasi berpengetahuan baik $(88,3 \%)$. Direkomendasikan kepada pihak sekolah agar meningkatkan penyuluhan kesehatan tentang kebersihan organ reproduksi saat menstruasi serta memberikan motivasi agar remaja putri dapat menjaga kebersihan organ reproduksi saat menstruasi.
\end{abstract}

Kata kunci: kesehatan reproduksi, menstruasi, motivasi, pengetahuan, remaja putri

\section{ABSTRACT}

Reproductive health of adolescent girls must be considered to avoid several diseases, including vaginal discharge, cervical cancer, genital irritation, allergies, inflammation and urinary tract infections. Good knowledge is needed for young women about reproductive health so as not to experience the disease. The purpose of this study was to determine the level of knowledge of young women in maintaining the reproductive health organs during menstruation at Mts.Pangeran Antasari Martapura in 2020. This study used a descriptive method with a cross sectional study design. The population in this study was all adolescent girls in grades VII, VIII, and IX which opened 131 people. The sampling technique was purposive sampling as many as 60 people. The research instrument used a questionnaire. The results showed that the level of knowledge of the respondents about menstruation (91.7\%), reproductive organ hygiene during menstruation (60\%), and how to maintain reproductive organ hygiene during menstruation with good knowledge (88.3\%). It is recommended to the school to improve health education to young women about the importance of maintaining the reproductive organ hygiene during menstruation and to provide motivation so that young women can maintain the reproductive organ hygiene during menstruation.

Key words: reproductive health, menstruation, motivation, knowledge, young women

Cite this as : Irianti, D. (2021). Tingkat Pengetahuan Remaja Putri dalam Menjaga Kebersihan Organ Reproduksi Saat Menstruasi. Jurnal Ilmu Kesehatan Insan Sehat, 9(1), 20-23.

\section{PENDAHULUAN}

Kebersihan diri saat menstruasi merupakan suatu perilaku yang bertujuan untuk menjaga kesehatan dan kebersihan organ reproduksi saat menstruasi. Kebersihan diri saat menstruasi diantaranya dapat dilakukan dengan cara penggunaan pembalut yang tepat dan membersihkan organ reproduksi saat menstruasi 4-5 kali dalam sehari. (Sharma, 2013; Kamath, 2013; Larasati \& Alatas, 2016).

Kebersihan diri saat menstruasi harus diperkenalkan sedini mungkin kepada remaja putri supaya tidak mengalami penyakit infeksi (Wartonah, 2015). Pengetahuan tentang kebersihan diri yang kurang dapat menyebabkan masalah kesehatan reproduksi seperti keputihan, Infeksi Saluran Kemih 
(ISK), penyakit radang panggul, dan kanker leher rahim (Septiani dan lina, 2014). Pengetahuan yang kurang tentang kebersihan diri juga dapat menyebabkan terjadinya pruritus vulva, yaitu timbulnya sensasi gatal yang parah pada organ reproduksi (Diana, 2009).

Pengetahuan yang kurang tentang kebersihan diri dapat diatasi diantaranya dengan cara penyuluhan kesehatan kepada remaja putri tentang cara menjaga kebersihan organ reproduksi saat menstruasi, dapat melibatkan teman sebaya atau orang lain yang sudah memiliki pengalaman menstruasi sebelumnya (Diana, 2009). Penelitian ini bertujuan untuk mengetahui tingkat pengetahuan remaja putri dalam menjaga kebersihan organ reproduksi saat menstruasi

\section{METODE}

Penelitian ini dilakukan secara deskriptif. Variabel penelitian adalah pengetahuan remaja putri dalam menjaga kebersihan organ reproduksi saat menstruasi. Populasi pada penelitian ini sebanyak 131 orang. Responden dipilih menggunakan metode pourposive sampling sebanyak 60 orang. Penilaian pengetahuan responden menggunakan kuesioner yang diisi melalui google form. Penelitiam ini dilakukan pada bulan November tahun 2020.

\section{HASIL}

Tabel 1. Distribusi Responden Menurut Karakteristik Responden di Mts Pangeran Antasari Martapura November $2020(n=60)$

\begin{tabular}{ccc}
\hline Variabel & $\mathbf{N}$ & $\mathbf{\%}$ \\
\hline Usia Responden & & \\
$11-12$ tahun & 13 & 21,7 \\
$13-14$ tahun & 38 & 63,3 \\
$15-16$ tahun & 9 & 15,0 \\
\hline Usia Menarche & & \\
10 tahun & 16 & 26,7 \\
11 tahun & 16 & 26,7 \\
12 tahun & 28 & 46,7 \\
\hline Total & 60 & 100 \\
\hline
\end{tabular}

Sumber: Data primer yang sudah diolah (2020)

Berdasarkan tabel 1, mayoritas responden berada pada rentang usia 13-14 tahun sebanyak 38 orang $(63,3 \%)$, dan usia menarche terbanyak pada 12 tahun yaitu 28 orang $(46,7 \%)$.

Tabel 2. Tingkat Pengetahuan Remaja Putri dalam Menjaga Kebersihan Organ Reproduksi saat Menstruasi di Mts. Pangeran Antasari Martapura November $2020(n=60)$

\begin{tabular}{lcc}
\hline \multicolumn{1}{c}{ Variabel } & N & \% \\
\hline Pengetahuan tentang menstruasi & & \\
Baik & 55 & 91,7 \\
Cukup & 5 & 8,3 \\
Kurang & 0 & 0 \\
\hline
\end{tabular}

Dewi Irianti, Tingkat Pengetahuan Remaja Putri dalam Menjaga

\begin{tabular}{|c|c|c|}
\hline Variabel & $\mathbf{N}$ & $\%$ \\
\hline $\begin{array}{l}\text { Pengetahuan tentang kebersihan } \\
\text { menstruasi }\end{array}$ & organ & reproduksi saat \\
\hline Baik & 36 & 60 \\
\hline Cukup & 18 & 30 \\
\hline Kurang & 6 & 10 \\
\hline
\end{tabular}

\begin{tabular}{lccc}
$\begin{array}{l}\text { Pengetahuanvtentang cara } \\
\text { reproduksi saat menstruasi }\end{array}$ & menjaga & kebersihan & organ \\
Baik & 53 & 88,3 \\
Cukup & 6 & 10 \\
Kurang & 1 & 1,7 \\
\hline \multicolumn{2}{c}{ Total } & $\mathbf{6 0}$ & $\mathbf{1 0 0 , 0}$ \\
\hline
\end{tabular}

Sumber: Data primer yang sudah diolah (2020)

Berdasarkan tabel 2, mayoritas responden memiliki pengetahuan yang baik tentang menstruasi sebanyak 55 responden $(91,7 \%)$, pengetahuan tentang kebersihan organ reproduksi saat menstruasi paling banyak sebesar 36 responden $(60 \%)$, dan pengetahuan tentang cara menjaga kebersihan organ reproduksi saat menstruasi terbanyak adalah 53 orang $(88,3 \%)$.

\section{PEMBAHASAN}

Mayoritas responden berada pada usia remaja menengah (13-14 tahun), yaitu masa peralihan dari usia anak menuju dewasa, dimana sudah dapat mengakses internet dengan mudah sehingga memudahkan remaja mendapatkan informasi dari berbagai sumber, termasuk internet. Hal ini sejalan dengan penelitian Fadhillah (2011), menyatakan bahwa usia remaja umur 13-15 tahun di Indonesia berada pada periode terakhir usia anak sudah memiliki kemampuan dalam memperoleh informasi melalui internet.

Usia menarche (haid pertama) terbanyak responden berada pada usia 12 tahun. Usia menarche biasanya terjadi pada usia 10-14 tahun, tetapi pada beberap kondisi bisa terjadi pada usia 9 tahun (Luthfiana, 2018). Hasil penelitian ini sesuai dengan penelitian Aulia (2009), menyatakan bahwa sebanyak $54 \%$ remaja mengalami haid pertama di usia $12-14$ tahun, sekitar $33,3 \%$ sebelum 12 tahun, serta $12,7 \%$ pada usia 9 dan 16 tahun. Usia menarche yang berbeda dapat disebabkan oleh faktor internal yaitu genetic, dan faktor eksternal seperti makanan, pola hidup serta status gizi.

Mayoritas pengetahuan responden tentang menstruasi adalah baik. Hal ini dapat berhubungan dengan responden yang telah mendapat informasi terkait menstruasi dari orang lain yang sudah pernah mengalami menstruasi, seperti ibu dan saudara di rumah, membaca informasi tentang menstruasi di internet, serta sudah pernah mendapat materi di sekolah tentang menstruasi (Diana, 2009). Pengetahuan seseorang dapat dipengaruhi dari faktor internal, yaitu umur, tingkat pendididkan, dan pengalaman serta faktor eksternal yaitu sumber informasi yang dapat diperoleh melalui pendidikan formal, nonformal, maupun 
informal (Lucyana, 2016). Menurut Permana (2016), menyatakan bahwa tingkat pengetahuan dipengaruhi oleh lingkungan, seperti teman, keluarga, dan masyarakat.

Pengetahuan yang baik akan dipengaruhi oleh banyaknya informasi yang didapat (Notoatmodjo, 2010). Hal ini sejalan dengan Leilina (2010), menyatakan bahwa semakin baik pengetahuan seseorang tentang menstruasi, maka semakin siap seseorang menghadapi menstruasi tersebut. Pengetahuan tentang menstruasi yang diberikan sejak usia dini dapat meningkatkan penerapan kebiasaan dan pengaruh yang baik dalam memelihara kebersihan organ reproduksi saat menstruasi (Tarhane dan Kasulkar, 2015).

Kesehatan organ reproduksi harus dijaga untuk mempertahankan fertilitas seseorang. Tubuh lebih banyak mengeluarkan keringat, minyak, dan cairan tubuh lainnya saat menstruasi, sehingga harus tetap dijaga kebersihan diri, terutama organ reproduksi, yaitu vagina (Kusmiran, 2012). Pengetahuan tentang perilaku dalam mempertahankan kebersihan organ reproduksi saat menstruasi sangat diperlukan karena menjadi salah satu faktor penentu kesehatan reproduksi seseorang (Ayuningtyas, 2011).

Personal hygiene saat menstruasi dilakukan dengan cara menjaga kebersihan genetalia, seperti mencuci organ reproduksi dengan air bersih secara teratur, menggunakan pakaian dalam yang dapat menyerap keringat dengan baik, segera mengganti pakaian dalam jika sudah penuh, mengganti pembalut minimal setiap 6 jam, dan mandi secara teratur (Pribakti, 2008). Manajemen Kebersihan Menstruasi (MKM) merupakan tindakan pengelolaan kebersihan dan kesehatan saat menstruasi. MKM dilakukan dengan cara penggunaan pembalut yang bersih, diganti secara teratur minimal 6 jam sekali dengan menyediakan akses pembuangan yang aman, dapat menggunakan toilet dan air bersih pada kondisi baik serta privasi yang terpelihara (UNICEF, 2015).

Hasil penelitian ini sejalan dengan penelitian Luthfiana (2018), yang menyatakan bahwa sebanyak $58,3 \%$ responden memiliki perilaku personal hygiene baik dan perilaku baik saat menstruasi sebanyak 53,3\%, dimana responden tersebut memiliki pengetahuan baik tentang personal hygiene saat menstruasi sebesar $68,3 \%$. Ada hubungan yang signifikan antara pengetahuan tentang personal hygiene saat menstruasi dengan perilaku personal hygiene dan perilaku baik saat menstruasi.

\section{KESIMPULAN}

Berdasarkan hasil penelitian, kesimpulan yang didapatkan yaitu mayoritas pengetahuan remaja putri tentang menstruasi berpengetahuan baik sebanyak 91,7\%. Pengetahuan responden tentang kebersihan organ reproduksi saat menstruasi terbanyak memiliki pengetahuan baik sebesar $60 \%$. Pengetahuan remaja putri tentang cara menjaga kebersihan organ reproduksi saat menstruasi paling banyak berpengetahuan baik sebanyak $88,3 \%$.

\section{SARAN}

Diharapkan penelitian ini memberikan manfaat terutama bagi remaja putri agar memahami pentingnya Personal Hygiene yang baik saat menstruasi.

\section{DAFTAR PUSTAKA}

Ayuningtyas, D.N. 2011. Hubungan antara Pengetahuan Menjaga Kebersihan Genitalia Eksterna dengan Kejadian Keputihan pada Siswi SMA Negeri 4 Semarang. Semarang: FK UNDIP.

Diana. 2009. Hubungan Antara Pengetahuan Kesehataan Reproduksi dengan Perilaku Higienis Remaja Putri Saat Menstruasi. Skripsi Universitas Muhammadiyah Surakarta

Fadillah, N. 2011. Pengaruh Pendidikan Kesehatan Terhadap Pengetahuan Siswi SMP Tentang Cara Menjaga Kebersihan Area Genetalia saat Menstruasi di SMP Negeri 6 Makassar. Skripsi. Universitas Hasannudin.

Kamath, R. et al. 2013. Global Journal Of Medicine And Public Health A Study On Knowledge And Practices Regarding Menstrual Hygiene Among Rural And Urban Adolescent Girls In Udupi Taluk, Manipal, India: 19.

Kusmiran, E .2012. Kesehatan reproduksi remaja dan wanita. Jakarta: Salemba Medika

Larasati, T.A, \& Alatas, F. 2016. Dismenore primer dan faktor risiko dismenore primer pada remaja. Majority. 5(3): 79-84.

Leliana. 2010. Hubungan Pengetahuan Remaja Putri terhadap Kesiapan dalam Menghadapi Menarche di SD Al-Azhar Medan. Skripsi. Program Studi DIV Bidan Pendidik Universitas Sumatera Utara.

Luthfiana. 2018. Analisis Kesiapan Siswi Sekolah Dasar Dalam Menghadapi Menarche. Jurnal Biometrika dan Kependudukan, 5(2): 135-145.

Lucyana, N. 2016. Gambaran Gangguan Menstruasi Pada Remaja Putri Dilihat Berdasarkan Kategori IMT/U Kelas VII di SMP Muhammadiyah 1 Yogyakarta.

Notoatmodjo, S. 2010. Metodologi Penelitian Kesehatan. Jakarta: Rineka Cipta.

Sharma, N., et al. 2013. A Cross ectional Study Of Knowledge, Attitude And Practices Of Menstrual Hygiene Among Medical Students In North India. The Journal of Phytopharmacology, 2(5): 2837.

Septiana., \& Lina. 2014. Hubungan Pengetahuan Remaja Putri Tentang Personal hygiene 
kewanitaan dengan Pelaksanaan Personal hygiene kewanitaan Pada Saat Menstruasi.

Permana. 2016. Tips Merawat Kebersihan Dan Kesehatan Vagina: Jakarta: Majalah Aulia.

Pribakti, B .2008. Tips dan Trik Merawat Organ Intim. Jakarta: Sagung

Tarhane., \& Kasulkar. 2015. Hubungan Tingkat Pengetahuan Tentang Mnestruasi Dengan
Dewi Irianti, Tingkat Pengetahuan Remaja Putri dalam Menjaga Kesiapan Menghadapi Menarche Pada Siswi Kelas V dan VI Di SD Negeri Dangkel Parakan Tenmanggung. Jurnal Kebidanan,3 : 16-22.

Tarwoto., \& Wartonah. 2015. Kebutuhan Dasar Manusia dan Proses Keperawatan Edisi 5. Jakarta: Salemba Medika.

UNICEF. 2015. Manajemen Kebersihan Menstruasi di Indonesia. Jakarta: Aliansi Remaja Independen 